\title{
Tonsillectomy by Diode Laser Versus Cold Steel Dissection Method in Children, Basra, South of Iraq
}

\author{
Rabeea Jabbar Atiyah ${ }^{1 *}$ and Hussam Haider Salman ${ }^{2}$ \\ ${ }^{1}$ ENT Head and Neck surgeon, Al-Habobi Teaching Hospital, Naseriyah, Iraq \\ ${ }^{2}$ RFRCS, DLO, Iraq
}

Submission: January 22, 2020; Published: January 28, 2020

*Corresponding author: Rabeea Jabbar Atiyah, M B Ch B, CABMS, ENT Head and Neck surgeon Al-Habobi Teaching Hospital, Naseriyah, Iraq

\author{
Abstract \\ Background: Tonsillectomy continues to be a commonly performed operation by the otolaryngologist, although many different methods \\ for tonsillectomy were developed.
}

Aim of study: To compare between tonsillectomy by diode laser and cold steel dissection regarding the operative time, post-operative pain and post-operative bleeding.

Method: The study included fifty tonsillectomies were performed in the ENT department of Basra General Hospital from February to December 2008. All patients were diagnosed as having chronic or recurrent tonsillitis. Any patient with acute infection or craniofacial anomalies was excluded from the study. The right tonsil dissected by diode laser whiles the left one by cold steel dissection. The average time of surgery was calculated and the post-operative pain at the night of surgery and two weeks later was noticed. data analysis was done by SPSS 11.0

Results: The mean time calculated for laser tonsillectomy was 4 minutes while by dissection method was 6.5 minutes with a statistically significant. about $84 \%$ of the tonsil that removed by Diode laser as being the most painful, while $10 \%$ of the tonsil that removed by dissection method as being most painful. In all patients under the study no post-operative bleeding was occurred so there is no difference between the two methods regarding the incidence of post tonsillectomy bleeding.

Conclusion: The diode laser significantly reduced the operative time but increased post-operative pain. There was no significant difference in the incidence of post-operative bleeding by the two methods.

Keywords: Tonsillectomy; Diode Laser; Cold Steel Dissection Method; Operative

\section{Introduction}

Tonsils are a part of the Waldayers ring, which is an aggregation of lymphoid tissue located in the nasopharynx and oropharynx at the entrance of the aerodigestive tract. It has an important role in children for its function in immunology and defense mechanism. Antibody secretion, and IgA production, plays a role in mucosal defense mechanism. In the early 20th century, tonsillectomy was the most popular operative procedure for treating various respiratory and systemic diseases [1]. There have been many different studies of methods of tonsils removal and hemostasis.

Probably the two most common techniques are dissection with cold instruments and electrosurgery. However, the dissection technique has remained the standard procedure for tonsillectomy for many years till now [2]. In the last years laser come in advance as a new method of tonsillectomy regarding its advantages to reduce operative time, post-operative pain and bleeding. In our study we used Diode laser to assist in tonsillectomy procedure and the intraoperative and postoperative outcomes is compared to the conventional dissection of tonsillectomy.

Laser is acronym for light amplification by stimulated emission of radiation, surgical lasers are devices that amplify light and create coherent light beams ranging from the infrared to the ultraviolet parts of the spectrum[3] Einstein postulated the theoretical foundation of laser action, stimulated emission of radiation, in 1917. In his classic journal article, "Zur Quantem Theorie der Strahlung" [i.e., "The Quantum Theory of Radiation"], he discussed the interaction of atoms, ions, and molecules with electromagnetic radiation.

He specifically addressed absorption and spontaneous emission of energy and proposed a third process of interaction: stimulated emission. Einstein postulated that the spontaneous 
emission of electromagnetic radiation from an atomic transition has an enhanced rate in the presence of similar electromagnetic radiation. This "negative absorption" is the basis of laser energy. Many attempts were made in the following years to produce stimulated emission of electromagnetic energy, but it was not until 1954 that this was successfully accomplished [4,5].

The reaction of laser energy with living tissue can be photo ablative, photochemical, photomechanical or photo thermal. Most lasers react with a combination of all these mechanisms although for a specific wavelength and delivery system one form of tissue reaction may predominant.

\section{Patients and Methods}

Across sectional study included fifty tonsillectomies were performed in the ENT department of Basra General Hospital during period from February to December 2008. All patients were diagnosed as having chronic or recurrent tonsillitis by the usual method of history taken and physical examinations. Any patient with acute infection, craniofacial anomalies or contra indications for anesthesia was excluded from the study. The investigations included $\mathrm{Hb} \%$ and GUE there was no need for farther investigations. Parents were told about the study nature of the procedure and their agreement was taken. The operation done under general anesthesia right tonsils were removed by diode laser and the left tonsils by standard steel dissection method. Patients were not told which tonsil was removed by laser.

Time needed for removal of each tonsil was calculated. Patients were asked at the night of surgery and two weeks later about the severity of pain whether more on the right or left sides of the throat and their responses were recorded. Post-operative bleeding both primary and secondary were looked for and the results recorded. All data were entered into a database by independent statistics personnel. Data were analyzed using the statistical package for the social sciences version 11.0 software (SPSS 11.0). The chi-square test and T- test were used to study associations between variables. the levels of significance were considered when equal or less than 0.05 .

Result

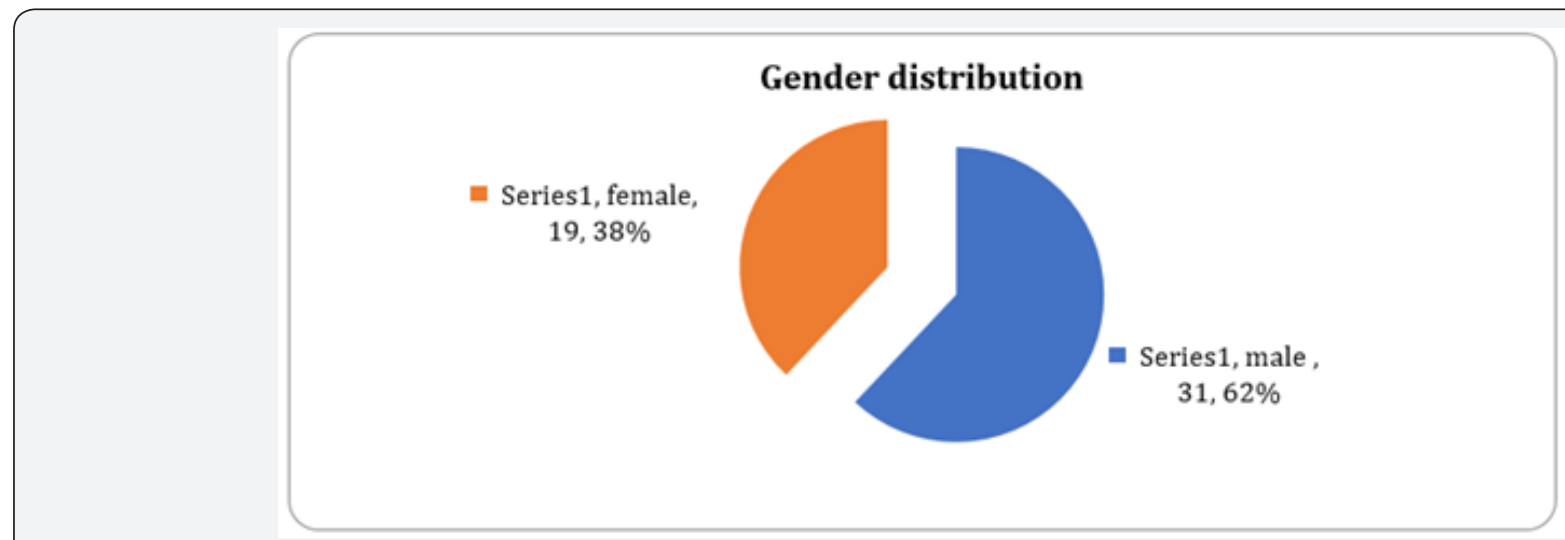

Figure 1: gender distribution of patients.

A total of 50 patients were done for them tonsillectomy, by two surgical method one for right side and other for left side [50], with mean age was $6.36 \pm 2.45$ year. male patient was 31 while female was 31 , as in figure 1 . The mean time calculated for laser

Table 1: Mean and SD of time consumed by the two methods.

\begin{tabular}{|c|c|c|c|c|}
\hline \multirow{2}{*}{ Type of Surgery } & \multicolumn{4}{c|}{ Average Time of Surgery [Minutes] } \\
\cline { 2 - 5 } & \multicolumn{3}{c|}{ Mean value } \\
\hline Laser Tonsillectomy & NO. & 4 & 0.82 & 0.01 \\
\hline Dissection Tonsillectomy & 50 & 6.5 & 1.2 & \\
\hline
\end{tabular}

The study reveal that on the evening of surgery about $84 \%$ of the patients identified the throat in which the tonsil was removed by Diode laser [the right side] as being the most painful, while $10 \%$ of the patients identified the throat in which the throat was removed by dissection method as being most painful, with statistically significant when p value 0.001 as shown in table 2 . tonsillectomy was 4 minutes while by dissection method was 6.5 minutes, there is a statistically significant difference for the time consumed by the two methods [p value 0.01 ] as shown in table 1 .
After two weeks following surgery the study was found that $81.5 \%$ identified the laser side as most painful side, $10.5 \%$ of the patients identified the side of dissection method more painful, A statistically significant[p value 0.001] number of patients chose the laser side as the most painful side two weeks after surgery as shown in table 3. 
Table 2: Pain distribution at evening of surgery.

\begin{tabular}{|c|c|c|c|c|c|c|}
\hline \multirow{3}{*}{$\begin{array}{l}\text { Type of } \\
\text { Surgery }\end{array}$} & \multicolumn{4}{|c|}{ Pain at Evening of Surgery } & \multirow{3}{*}{$\begin{array}{c}\text { Total } \\
\text { No. }\end{array}$} & \multirow{3}{*}{$P$ value } \\
\hline & \multicolumn{2}{|c|}{ Present } & \multicolumn{2}{|c|}{ Absent } & & \\
\hline & No. & $\%$ & No. & $\%$ & & \\
\hline $\begin{array}{c}\text { Laser } \\
\text { Tonsillectomy }\end{array}$ & 42 & 84 & 8 & 16 & 50 & 0.0001 \\
\hline $\begin{array}{r}\text { Dissection } \\
\text { Tonsillectomy }\end{array}$ & 5 & 10 & 45 & 90 & 50 & \\
\hline
\end{tabular}

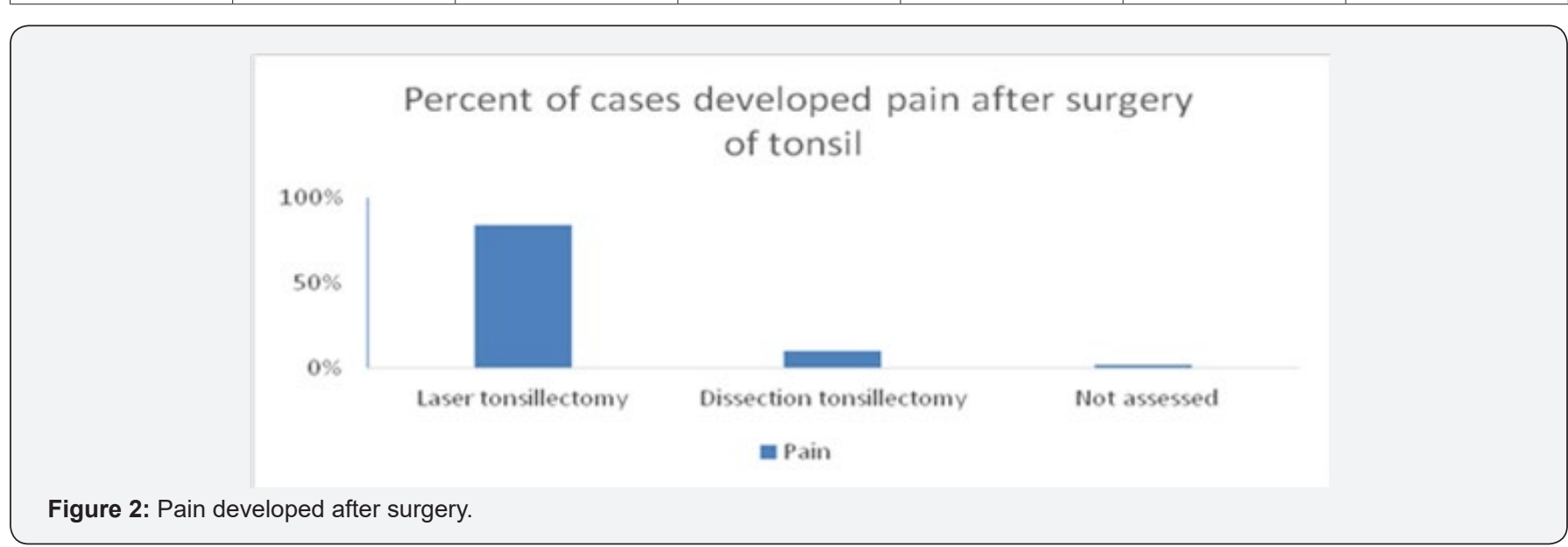

Table 3: Pain distribution after 2 weeks of surgery.

\begin{tabular}{|c|c|c|c|c|c|c|}
\hline \multirow{3}{*}{ Type of Surgery } & \multicolumn{4}{|c|}{ Pain after 2 Weeks of Surgery } & \multirow{3}{*}{$\begin{array}{c}\text { Total } \\
\text { No. } \\
\end{array}$} & \multirow{3}{*}{$P$ value } \\
\hline & \multicolumn{2}{|c|}{ Present } & \multicolumn{2}{|c|}{ Absent } & & \\
\hline & No. & $\%$ & No. & $\%$ & & \\
\hline Laser Tonsillectomy & 41 & 82 & 9 & 18 & 50 & 0.0001 \\
\hline Dissection Tonsillectomy & 6 & 11 & 45 & 90 & 50 & \\
\hline
\end{tabular}

In general, the study revealed that pain after tonsillectomy whether at evening or 2 week later from operation was more than $80 \%$ by laser and $10 \%$ by dissection and about $2 \%$ was not assessed as shown in figure 2 . In all patients under the study no post-operative bleeding was occurred so there is no difference between the two methods regarding the incidence of post tonsillectomy bleeding.

\section{Discussion}

Tonsillectomy continues to be a commonly performed operation by the otolaryngologist [6], although many different methods for tonsillectomy were developed. There are still controversies over what is the optimal technique for tonsillectomy with the lowest morbidity rates. various techniques have been developed to improve post-operative morbidity \& many studies have been performed to compare the new procedure with the conventional methods [7-9].

The first clinical experience with laser tonsillectomy was reported in 1972 but it is only recently that the use of laser has been widespread [10]. Many different types of lasers were used for tonsillectomy each has its unique physical properties KTP,
ND YAG, CO2 in addition to diode laser. Diode laser has similar physical prosperities to Nd-yag laser but is superior to $\mathrm{Nd}$ yag laser because of less heat effect to collateral structures [11]. The cutting or vaporizing action of diode laser is achieved by a (red hot cautery effect), this allow very delicate cutting and destruction of tissue with very little lateral damage and seems that it is very useful for tonsillectomy [12].

The diode laser emits laser light at a wavelength of $810 \mathrm{~nm} 14$ this means that good deep coagulation of up to $1 \mathrm{~cm}$ depth of tissue can be achieved [13]. The use of small fibers in contact mode in diode laser makes the dissection very gentle and is likely that this will lead to reduction of post-operative morbidity [14]. The operative time needed for tonsillectomy by diode laser is significantly reduced in comparison with dissection method in our study, which goes with the results of Saito et al. [15], and Auf et al. [16]. Who compared KTP laser tonsillectomy with dissection method, although these results are against the findings of both Strunk et al. [17]? And Kothari et al. [18]. who also used KTP laser in comparison with dissection tonsillectomy and this probably due to increased laser set up time and malfunction which is not a problem in diode laser because diode laser machine is small, 
compact, portable, efficient, relatively quiet, and very simple to use, it has a stable power output and expected long life, no instillation cost and virtually maintenance free [19].

Post-operative pain at the night of surgery was more in diode laser side in comparison with the dissection side $[\mathrm{P}<0.05]$, which is against the result of Saito et al. [15], Auf et al. [16], and Aos et al. [10]. This is probably due to hot cautery effect of Diode laser which lead to more post-operative pain in comparison with cold dissection while other types of lasers have a sealing action on the fine peripheral nerve endings that result in a lowering of subjective pain post operatively $[20,21,22]$. Two weeks later post-operative pain in diode laser side was still more than the dissection side $[\mathrm{P}<0.05]$, which is the same result of Saito et al. [15], Kothari et al. [23], Auf et al. [16], and Aos et al. [10]. This probably due to 2ndry opportunistic infection, which is more in laser side, such an infection might be greater than the infection in dissection side where there is no layer of thermal necrosis by laser [23]

In our study no post-operative bleeding occurred whether primary or 2ndary so there was no difference of post-operative bleeding between the two methods which goes with result of Shrunk et al. [17], D Eredita et al. [24], and Saito et al. [15] but is against the results of Kothari et al. [18], and Auf et al. [16]. where there was more post-operative bleeding with laser than dissection method and this probably is related to surgeons experience in using the laser \& to the type of laser used.

\section{Conclusion}

We conclude that there is significant decrease in operative time with diode laser but there is more post-operative pain with no difference in both dissection and diode laser tonsillectomy regarding incidence of post-operative bleeding. We found the main advantage of diode laser tonsillectomy is to decrease operative time which is cost effective and important especially in children patients with poor general health.

\section{References}

1. Kornblut AD (1987) A traditional approach to surgery of the tonsils and adenoids. Otolaryngol Clin North Am 20: 349-63.

2. MacBeth RG, Hadfield E H, Macbeth R G (1950) The tonsil problem. J Laryngol 64: 591-98.

3. Bingham Brian JG (2008) Scott-brown otolaryngology, head and neck surgery, $7^{\text {th }}$ ed. 1 , chapter 58 , pp. 742 .

4. Ossoff Robert h (2005) Cummings Otolaryngology: Head and Neck Surgery $4^{\text {th }}$ Revised edition [Hardback], chapter 7, p 214. Laser surgery basic principles and safety considerations.

5. Lalawani Anil (2007) Current diagnosis and treatment otolaryngologyHead and neck surgery, $2^{\text {nd }}$ ed., chapter 5 . Laser in head and neck surgery.

6. Franco K L, R B Wallace (1987) Management of post-operative bleeding after tonsillectomy. Otolaryngologic clinic of north America 20(2): 391.
7. Leach J, Steven Schaefer, Scott Manning (1993) Comparison of two methods of tonsillectomy. Laryngoscope 103: 619-22.

8. Back l, et al. (2001) traditional tonsillectomy compares with bipolar radiofrequency thermal ablation tonsillectomy in adult. Archive of otolaryngology head and neck surgery 127: 1106-1112.

9. Raut v, et al. (2001) bipolar scissors vs cold dissection tonsillectomy. Laryngoscope 111: 2178-2182.

10. Oas R, Bartels P (1990) KTP-532 laser tonsillectomy comparison with dissection method. Laryngoscope 100: 385-388.

11. Rabul K Shah, Babak Nemati, Lihong V Wang, Stanley M Shapshay (2001) Optical-thermal simulation of tonsillar tissue irradiation. Laser surgery med 28: 313-319.

12. Maloney RW (1991) Contact nd-yag tonsillectomy effect on weight loss recovery. Laser surgery med 11: 517-522.

13. Jacques S L, Rastegar S, Montamedi M (1991) Liver photocoagulation with diode laser $805 \mathrm{~nm}$ vs. nd-yag $1064 \mathrm{~nm}$. photo chem photobiology 53: 825-835.

14. Dilkes M G, Cameron I, Quinn S J, G S Kenyon (1994) preliminary experience with $810 \mathrm{~nm}$ wavelength diode laser in ENT surgery. Laser in medical science 9: 261-264.

15. Saito T, Honda N, Saito H. (1999) Advantage \& disadvantage of KTP laser tonsillectomy compare with dissection. Auris Nasus Larynx 26(4): 447-452.

16. Auf I, Osbome J E, Sparkes C, Khalil H (1997) Is the KTP laser effective in tonsillectomy? Clinical otolaryngology and allied science 22: 145146.

17. Strunk CL, Nichols NL (1990) A comparison of the KTP/532-laser tonsillectomy vs. traditional dissection/snare tonsillectomy. Journal of otolaryngology H\&N surgery 103(6): 966-971.

18. Kothari P, Patel S, Brown P, Obara L, O Malley S (2002) A prospective double-blind randomized control trial comparing the suitability of KTP laser tonsillectomy with conventional dissection tonsillectomy for day case surgery. Clinical otolaryngology and allied science 27: 369-373.

19. Emmanuelle Ferri, Enrico Armato (2008) Diode laser microsurgery for the treatment of Tis \& T1 glottic tumor. American journal of otolaryngology head and neck surgery 29: 101-105.

20. Apfelberg D B, Maser M R, Lash H, White DN (1985) Benefit of the $\mathrm{CO}_{2}$ laser in oral hemangioma excision. Plastic reconstruction surgery 75 : 46-50.

21. McDonald G A, Smpson G T (1983) Transoral resection of lesions of oral cavity with CO2 LASER. Otolaryngology clinic of north America 16: 839-847.

22. Carruth J A S (1982) Resection of tongue with laser. Journal of otolaryngology 96: 529-543.

23. AL rubeai T M (1997) Co2 laser tonsillectomy: A comparison with standard technique. A thesis submitted to the scientific council of otolaryngology in partial fulfillment for the degree of fellowship of Iraqi commission for medical specialty.

24. D Eredito R, et al. (2004) Contact diode laser tonsillectomy in children. Otolaryngology head and neck surgery 131: 732-735. 


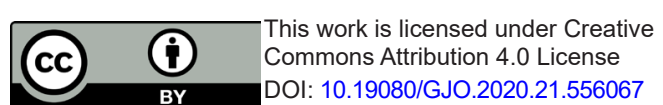

Commons Attribution 4.0 License

BY DOI: 10.19080/GJO.2020.21.556067

\section{Your next submission with Juniper Publishers will reach you the below assets}

- Quality Editorial service

- Swift Peer Review

- Reprints availability

- E-prints Service

- Manuscript Podcast for convenient understanding

- Global attainment for your research

- Manuscript accessibility in different formats

( Pdf, E-pub, Full Text, Audio)

- Unceasing customer service

Track the below URL for one-step submission https://juniperpublishers.com/online-submission.php 